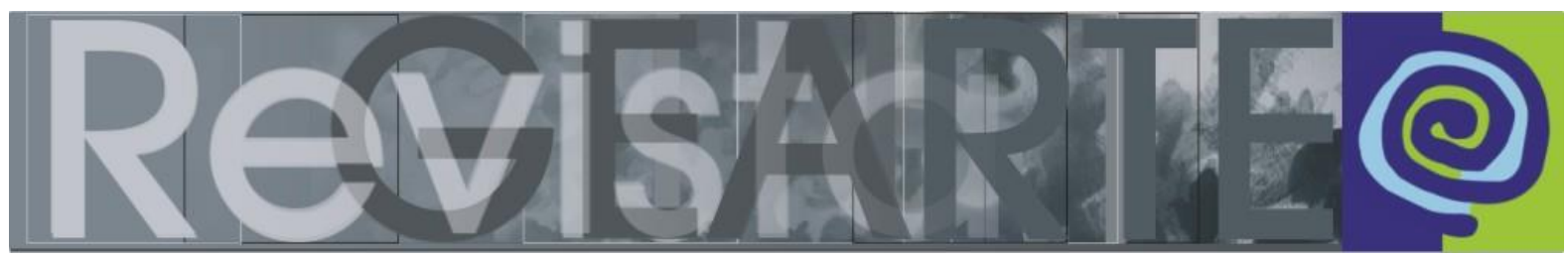

\title{
O círculo (Isabel Allende), o quadrado (Antonio Dias) e o triângulo (Ana Mae Barbosa)
}

Terezinha Losada (Universidade Federal do Estado

do Rio de Janeiro - UNIRIO, Rio de Janeiro/RJ, Brasil)

RESUMO - O círculo (Isabel Allende), o quadrado (Antonio Dias) e o triângulo (Ana Mae Barbosa) - Cotejado pelas obras de Isabel Allende e Antonio Dias, este artigo discute o exercício de teoria aplicada que tenho desenvolvido em minha prática e em pesquisas no ensino de arte, relacionando-o à Abordagem Triangular (Barbosa), ao ensino de Língua Portuguesa e à Semiótica (Santaella, Peirce e Jakobson).

PALAVRAS-CHAVE

Abordagem Triangular. Teoria aplicada. Semiótica.

RESUMEN - El círculo (Isabel Allende), el cuadrado (Antonio Dias) y el triángulo (Ana Mae Barbosa) - Este artículo, cotejado por las obras de Isabel Allende y Antonio Dias, discute el ejercicio de teoría aplicada que he desarrollado en mi práctica y en investigaciones en la enseñanza del arte, relacionándolo al Abordaje Triangular (Barbosa), a la enseñanza de la Lengua portuguesa y a la Semiótica (Santaella, Peirce y Jakobson).

PALABRAS CLAVE

Abordaje Triangular. Teoría aplicada. Semiótica.

Creio que como eu a maioria dos professores tem a mania, ou a necessidade, de arrumar pastas e gavetas cheias de papeis no início do ano. Nesse processo de arquivamento e descarte de coisas recentes me apareceu, não sei como, o folder do programa educativo de uma exposição que elaborei em 2001. Deixei-o em cima da mesa com preguiça de pegar a escada para colocá-lo numa das caixas de arquivo morto que ficam no fundo do compartimento superior do guarda roupa do quarto de hóspedes, ufa!!!

Mas dizem que nada acontece por acaso. Aliás, descansando dessa arrumação que atravessou o dia, e me esquivando de iniciar este artigo, revi naquela noite o filme Casa dos Espíritos, baseado no livro de Isabel Allende. Como um círculo, símbolo do cosmo por não ter começo nem fim, o filme inicia e acaba com o percurso de um fusca vermelho numa estrada ressequida. Nesse trajeto, entre eventos surreais ou místicos, ao tempo que se conta a estória de gerações de uma família, marcadamente de suas 
mulheres, também se faz uma revisão crítica e humanista do violento golpe militar ocorrido no Chile, em 1973.

Seja por acaso, providência divina, ou estritamente por conexão poética, o folder em questão se refere à exposição retrospectiva da obra de Antonio Dias, artista que explora diversos sentidos de territorialidade, recorrendo a forma do quadrado ao longo de sua obra. A exposição foi realizada pela Galeria ECCO, em Brasília, tendo como título: O País Inventado. Que pais é esse? No citado folder ${ }^{1}$ encontramos o seguinte texto:

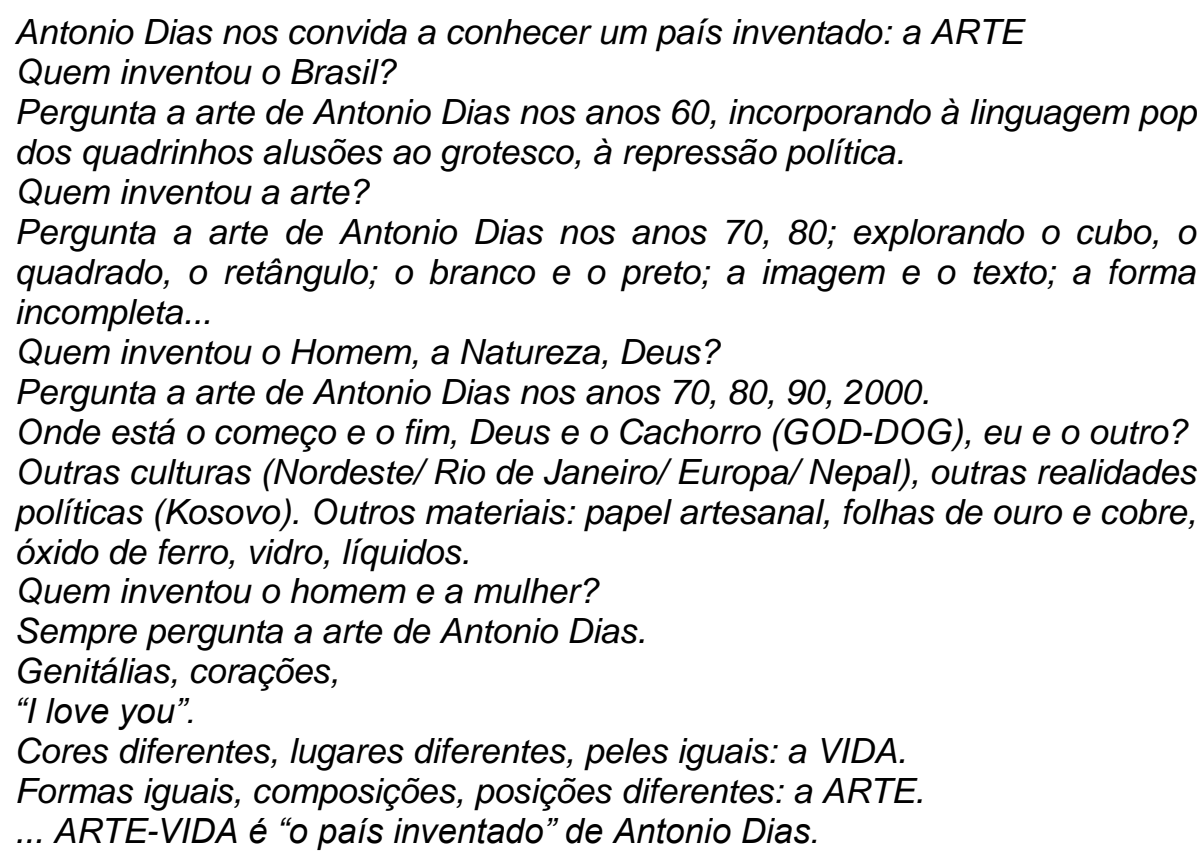

Depois de várias tentativas frustradas de iniciar este artigo, olhei para o folder em cima da mesa e decidi que iria discutir a Abordagem Triangular, formulada pela instigante e querida professora Ana Mae Barbosa, a partir dessa minha experiência educativa. O triângulo é o símbolo da conjunção sinergética da diferença. Além de várias religiões, muitas são as teorias pautadas na estrutura triangular, como ocorre em Kant, Hegel, Marx, Freud; bem como a rede de triangulações da Semiótica de Peirce. Ana Mae, por sua vez, propõe para o ensino de arte a integração dinâmica entre o Apreciar, o Fazer e o Contextualizar.

\footnotetext{
1 Na exposição de Antonio Dias fui responsável apenas pela concepção do programa educativo, sua execução foi realizada pela excelente arte-educadora Ana Maria Frade e o folder contava ainda com um breve e muito articulado texto crítico de Ligia Canungia.
} 
Figura 1 - Antonio Dias. Do it yourself: Freedom Territory, 1968-2011.

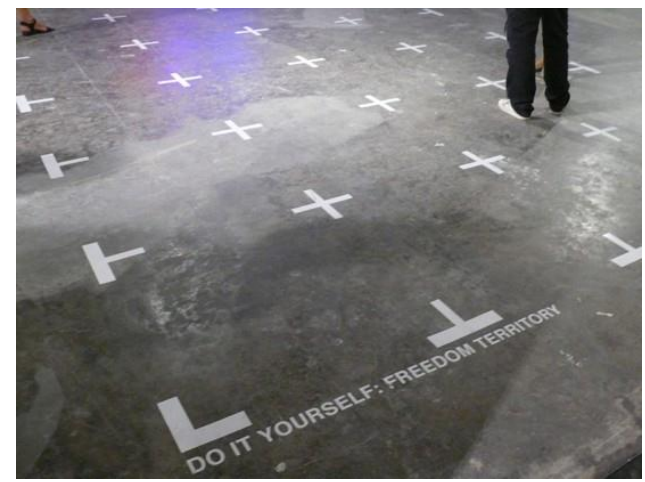

Fonte: Catálogo da exposição de Antonio Dias, Brasília, Galeria ECCO, 2001.

Uma peculiaridade do programa educativo sobre a exposição de Antonio Dias, que o distingue de outros que fiz e do modo como geralmente são feitos, deve-se ao fato de que a oficina de arte realizada com os alunos visitantes não ocorria ao final da visita, mas antes de iniciá-la. Esta "abordagem", iniciando o programa educativo pelo Fazer, já nos remete à dinâmica da "estrutura" triangular proposta por Ana Mae. Pois, para ela, não há uma ordem fixa para a exploração dos três vértices no planejamento didático, o importante é que todos eles sejam contemplados e de modo articulado.

Deve-se notar que a chamada Pedagogia Tradicional também adota uma "metodologia" triangular. Porém nela, invariavelmente, o professor inicia a aula fazendo uma explanação sobre o conteúdo curricular. Depois, ele "aprecia" alguns exemplos, teoréticos ou "contextuais", para facilitar a compreensão daquele tema pelos alunos. Por fim, o aluno deve "fazer" uma bateria de exercícios para fixar a aprendizagem, prática que culmina na realização da temível prova. A lógica desse encadeamento didático é atávica na educação escolar e, por isso, sobrevive - como os fantasmas de Isabel Allende - mesmo em propostas educativas que visam superar a Pedagogia Tradicional.

Por outro lado, vale lembrar que os princípios da experimentação, da formulação e solução de problemas, da expressão do aluno, da criatividade, propostos pela Escola Nova, nunca foram acolhidos pelo racionalismo do sistema educacional, exceto no ensino de arte, como se apenas nesse território tais princípios fossem necessários e válidos. Isso apenas ratifica a "esquizofrenia" da Educação, no sentido estrito de "cisão das funções mentais" que define esse termo. Embora achássemos que mesmo assim o ensino de arte poderia "salvar" a educação, de fato, a arte 
adoeceu na escola, tornando-se, paulatinamente, um livre fazer por fazer, sem qualquer conexão com nada.

Foi buscando enfrentar esta situação que na década de 1980 surgem em várias partes do mundo muitos debates e pesquisas sobre novas metodologias para o ensino de Arte. Não pretendo fazer aqui uma revisão histórica dessas propostas, mas apenas situar alguns aspectos que se tornaram determinantes no desenvolvimento do meu trabalho como professora. Nessa perspectiva, identifico duas tendências muito claras entre essas novas pesquisas metodológicas, as quais podem ser sintetizadas por meio dos dilemas de Ana Mae sobre a nomenclatura de um dos vértices de seu triângulo: "conhecer" ou "contextualizar"?

Embora muito heterogênea, aquilo que empresta coesão à vertente contextual é o interesse em relacionar o ensino de arte com a vida, considerando as questões da diversidade humana (raça, gênero, orientação sexual, idade etc.), de suas diferentes manifestações culturais, dos fazeres cotidianos e o impacto da cultura de massa, especialmente entre os jovens. Fundamentam suas propostas as teorias culturais, sociais e os debates sobre a pós-modernidade, que eclodem na mesma década de 1980.

Também muito diversificada, a tendência associada ao termo "conhecer" tem como ponto de convergência o interesse de se inscrever no ensino de arte escolar, desde a infância, o acesso ao corpo de conhecimentos próprios do campo da arte, tal como ocorre no ensino das demais disciplinas curriculares. Com esse propósito, além da prática artística, há o resgate de teorias e práticas que até então só eram contempladas nos cursos técnicos e superiores de arte, tais como a Estética, a História da Arte e a Crítica de Arte. O "Ensino de Arte Baseado em Disciplinas" (DBAE) é a manifestação mais emblemática dessa tendência. No entanto, muitas outras propostas surgem nesse período articulando os nexos teóricos requisitados acima a partir da análise da imagem (leitura visual), vertente com a qual me identifico, conforme será discutido no final desse texto.

De modo muito coerente com sua formação intelectual, estreitamente ligada às concepções de Paulo Freire, Ana Mae substitui o termo "conhecer" por 
"contextualizar", na configuração final de sua proposta. Porém, isso não significa a opção por uma dessas tendências, mas antes um esforço em articulá-las metodologicamente.

Pois, como ocorre nas poéticas de Isabel Allende e de Antonio Dias, a "contextualização" nas formulações educacionais de Ana Mae também é um exercício holístico. Para ela, o fazer e o apreciar visam desencadear uma elaboração existencial e cognitiva, que envolva a descoberta e a memória, a imaginação e a história, a afetividade e a crítica, a experimentação e o código, o individual e o coletivo... Em suas formulações teóricas não há qualquer distinção entre o erudito, o popular ou a cultura de massa. Tais opções dependem apenas do tipo de "abordagem" que o professor queira fazer no seu planejamento didático. Aliás, em sua prática educativa, Ana Mae sempre abordou essa diversidade de manifestações culturais e artísticas, seja em suas aulas ou nos eventos que organiza e, especialmente, quando dirigiu o Museu de Arte Contemporânea da Universidade São Paulo (MAC/USP).

Sintonizada com as discussões de seus pares, no Brasil e no mundo, ela sempre defendeu também, como uma bandeira epistemológica e política, a especificidade do campo de conhecimentos ligados à arte. Ana Mae sempre destacou a importância da "alfabetização visual" como um processo que resulta da apreciação dos aspectos sintáticos, semânticos e históricos das obras de arte e demais signos visuais que, por consequência, amplia o repertório expressivo e crítico dos estudantes. Em torno desses princípios ela tornou-se uma ativista política, congregando os arteeducadores na luta pela garantia do espaço disciplinar da arte na legislação educacional brasileira. Conquista essa, hoje ameaçada e sob alto controle ideológico, a pretexto de se des-ideologizar a educação. Que país é esse?

No entanto, conforme foi mencionado anteriormente, os fantasmas da pedagogia tradicional são atávicos, de modo que muitas e muitas propostas educativas que se dizem pautadas na triangulação proposta por Ana Mae, de fato sucumbem nas cisões esquizofrênicas do tradicionalismo. O sintoma mais raso e recorrente desse problema é o professor iniciar a aula fazendo uma "explanação" sobre a vida e a época de determinado artista, depois mostrar várias de suas obras, fartamente disponíveis na internet, elegendo, ele mesmo, uma delas para ser 
"apreciada" com os alunos. Feito isso, os alunos são convidados a "fazer uma cópia" daquela obra, a título de releitura.

O exercício metalinguístico, subjacente ao conceito de "releitura" utilizado por Ana Mae, é muito mais fecundo e dinâmico do que a realização de uma simples cópia. Mesmo assim, devo confessar que sempre me emociono vendo as cópias que as crianças fazem. Como é lindo o território da infância! Também me emociono e tenho profundo respeito pelo trabalho desses professores, que num jogo de ensaio e erro, fonte autêntica da construção do conhecimento, ousam buscar novos caminhos para a educação. Como é capcioso o território da tradição!

$\mathrm{Na}$ oficina de arte que antecedia a visita à exposição de Antonio Dias foi realizado um exercício, quase velado, de metalinguagem. $O$ texto do folder anunciava:

No trabalho de Antonio Dias há certos elementos formais que se repetem. Eles criam uma espécie de código, de alfabeto, de modo que variando a combinação desses elementos são criadas novas obras, novas fases, novos significados. Antes de visitar a exposição, vamos explorar as possibilidades de combinação desses elementos na oficina de arte.

Utilizando-se a técnica de máscara de impressão, muito comum na estamparia de tecidos e em alguns grafites urbanos, copiadas e recortadas (vazadas) nas máscaras a forma de nove elementos recorrentes na obra de Antonio Dias (Figura 2). Desse modo, com um rolinho de pintura e tinta guache os alunos podiam imprimir sucessivamente essas formas sobre o papel Kraft, criando suas composições.

Figura 2 - Padrões geométricos, padrões orgânicos, símbolos relacionais.

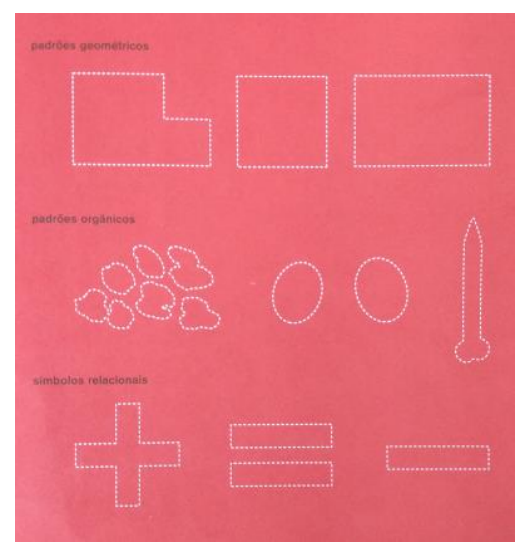

Fonte: Catálogo da exposição de Antonio Dias, Brasília, Galeria ECCO, 2001. 
Este exercício metalinguístico facilitou, em muito, a posterior discussão da exposição de Antonio Dias, artista geralmente considerado pela crítica de arte como sendo detentor de uma obra bastante hermética e conceitual. A primeira obra da exposição (Figura 1), "DO IT YOURSELF: FREEDOM TERRITORY" (Faça você mesmo: território liberdade), impressa no piso da entrada da galeria, já remetia ao trabalho feito na oficina, suscitando ao longo da visita inúmeras outras reflexões metalinguísticas, entre as "releituras" que o artista faz sobrea sua própria obra e a "pré-leitura" feita pelos estudantes.

Visando discutir melhor a importância das atividades metalinguísticas no ensino de arte e também aprofundar as discussões sobre o "conhecer" e o "contextualizar", iniciadas acima, irei recorrer a um paralelo com o ensino de Língua Portuguesa, comparação que em si mesma já é um exercício metalinguístico. No viés da Pedagogia Tradicional, além de preservar aquela metodologia de ensino já apresentada (explanação teórica / exemplos /exercícios), o ensino da linguagem verbal guarda ainda uma outra triangulação muito específica: a subdivisão entre gramática, literatura e redação.

A principal demanda das recentes formulações para o ensino de Língua Portuguesa (MEC, 1998) é exatamente romper essa fragmentação disciplinar tradicional, em especial, a supremacia da gramática, sempre abordada como um conhecimento autônomo e estritamente escolar. Nesse sentido, postulam que o conhecimento gramatical deve ocorrer de modo contextualizado, por meio da leitura e produção de textos. Ademais, o campo da leitura passa a ser denominado como "gêneros literários" de modo que, além da literatura estrito senso, também sejam lidos e escritos na escola outros tipos de textos, presentes no cotidiano.

Deve-se notar que esta nova triangulação, articulada e contextualizadora, configura uma mudança metodológica radical, que subverte um modelo secular do ensino de Língua Portuguesa. É devido a flagrante similaridade entre a proposta acima e as formulações de Ana Mae, que considero a substituição do termo "Metodologia" por "Abordagem", no título de sua proposta, um gesto de generosidade, feito por ela apenas para não se conflagrar com aqueles que achavam pretenciosa a primeira nomenclatura. Talvez porque o ensino de arte escolar estivesse tão 
desestruturado, no seu fazer por fazer (laissez faire), que o resgate da estrutura disciplinar tradicional se Ihes apresentasse como a única saída, sem dimensionarem os danos da fragmentação disciplinar no interior do ensino de linguagem, bem como na educação em geral. Por isso, ouso dizer que as duas propostas - a de Ana Mae e a de Língua Portuguesa - são métodos estruturais pós-estruturalistas, exatamente por subverterem o racionalismo esquizofrênico das cisões cognitivas construídas na modernidade.

Por outro lado, semioticamente, sei que não há pensamento sem estrutura, sem código, sem conceitos. Isto é, sem aquela rede de triangulação observada por Peirce (1977). Nela o processo cognitivo resulta sempre do impacto de uma impressão qualquer (Primeiridade), a qual pode ser simplesmente esquecida; ou então, provocar um estranhamento, suscitando relações (Secundidade), que também podem ser simplesmente descartadas; ou então, enfrentadas, construindo-se um novo conceito (Terceiridade). Este último, permanecerá estável em nossa mente como um conhecimento construído (conceito, regra, teoria, lei), a menos que seja abalado por um novo impacto, gerando novas relações, que sejam sedimentadas em novos conceitos; e assim infinitamente.

Esta dinâmica triangular da semiótica de Peirce é necessária desde a construção do conceito de um simples substantivo, que denomina uma coisa, apartando-a e relacionando-a às demais coisas do mundo, como fez Antonio Dias na obra "GOD-DOG", até a elaboração das mais complexas teorias filosóficas, científicas e educacionais.

Em 1994, estudando para o meu trabalho de mestrado, que tratou das vanguardas artísticas, me deparei com o texto "Por uma classificação da linguagem visual", de Lucia Santaella (1989). Além de me ajudar muito naquela pesquisa em curso, essa leitura mudou radicalmente minha atuação como professora. Como um exercício de teoria aplicada, ou seja, de teoria contextualizada, neste texto Santaella utiliza os conceitos de Ícone (Primeiridade), Índice (Secundidade) e Símbolo (Terceiridade), formulados por Peirce, na análise de obras de arte e outros tipos de signos. Sob o "impacto" dessa leitura, percebi sua estreita "relação" com as formulações de Ana Mae, em particular sobre a apreciação, e "concluí" que poderia 
fazer esse mesmo exercício de teoria aplicada, explorando diversos outros autores, inclusive para discutir a História da Arte com meus alunos.

Em linhas gerais, ao invés de apresentar aos estudantes as interpretações e análises feitas por grandes teóricos e historiadores da arte, passei a apresentar-Ihes apenas os principais conceitos e critérios metodológicos desses autores, estimulandoos a pensarem "junto com os teóricos", para construírem suas próprias interpretações (semioses) sobre a arte e demais signos da cultura visual. Isso não exclui a transmissão de informações teóricas e históricas pelo professor, mas apenas que seu acesso passa a ocorrer de modo contextualizado. Isto é, por meio da leitura e produção de imagens.

No âmbito propriamente da apreciação, passei a utilizar os conceitos de Peirce, já brevemente comentados, e também do linguista Roman Jakobson (1969). Sua teoria é baseada nos elementos do processo comunicativo (Mensagem, Emissor, Receptor, Referencial, Canal e Código) com o propósito de estabelecer critérios, minimamente objetivos, para a análise dos usos concretos da linguagem. Usos esses que, devido à sua diversidade, não eram até então considerados um objeto passível de análise pelas teorias da linguagem. Exatamente por isso, sua teoria teve grande repercussão na crítica literária e das artes em geral.

Discuto suas formulações a partir da apreciação de obras ligadas à tradição artística e, principalmente, exemplos da arte contemporânea, além de projetá-las na análise de imagens da cultura visual, geralmente fotos e publicidades de revistas. Explico aos alunos que a imagem é a Mensagem a ser desvelada e, como adverte Jakobson", deve-se analisar aquilo que foi "selecionado" e "combinado" para fazê-la. Em outras palavras, nosso objetivo é investigar a Função Poética da obra, independente de gostarmos ou não dela, de modo que esta não é uma classificação interpretativa válida, mas, outrossim, a nossa incógnita.

2 Jakobson (1969, p. 134) argumenta que: "A função poética projeta o princípio da equivalência do eixo da seleção para o eixo da combinação. A equivalência é promovida à condição de recurso constitutivo da sequência". 
É importante observar que dois fatores do processo comunicativo facilitam muito a abordagem da produção artística contemporânea, sempre refratária aos cânones interpretativos da tradição. O Canal, pois desde a obra Fonte de Duchamp a experimentação de novos materiais e suportes passou a ser sistemática na produção artística, como ocorre nos trabalhos de Dias. E também o Receptor, devido à correlata dissolução do conceito de autoria (Emissor), instigando uma efetiva participação do público, caso dos happenings e de muitas performances, instalações ou obras, conforme propõe Dias no seu Freedom Territory.

Quanto à tradição artística, é notória a ênfase no Referencial entre as obras naturalistas e realistas. As tendências expressionistas enfatizam o Emissor. Ao passo que o Código se destaca na racionalidade idealista das composições do alto Renascimento, do Abstracionismo Geométrico e do Minimalismo. Estas tendênciasNaturalismo, Expressionismo e Idealismo - foram exploradas didaticamente por Fayga Ostrower (1984), autora muito disseminada entre os arte-educadores e com a qual trabalho sempre, especialmente fazendo essas relações entre diferentes teorias.

Para além dessa ênfase "idealista", discernida por Ostrower, a tônica no Código determina também a Função Metalinguística, conforme definida por Jakobson. Esse é um terceiro aspecto muito importante para a discussão da produção artística contemporânea. Pois, de modo metalinguístico, uma das principais questões da produção artística contemporânea é a discussão do próprio conceito de arte, como fez Duchamp e faz Antonio Dias.

No entanto, é preciso frisar que a aplicação dos conceitos de Peirce e Jakobson não visam circunscrever a arte numa determinada classificação. Muito ao contrário, seu objetivo é apreciá-la por diversos ângulos. Sempre advirto aos alunos de que não há uma classificação única ou correta; o importante é relacionarem as suas impressões àquilo que o artista efetivamente "selecionou" e "combinou" na criação da obra. Devido a essa característica de se analisar, ao mesmo tempo, obras de várias épocas e tradições, tal como estas se apresentam ao aluno na atualidade, denomino essa abordagem como Olhar Sincrônico. 
Nessa mesma perspectiva de teoria aplicada, no Olhar Diacrônico, exploro autores que permitam a discussão do desenvolvimento histórico da arte ocidental hegemônica. No entanto, devido à autonomia dos estudos de cada um desses autores, essas oficinas podem ser exploradas em sala de aula de modo isolado, sem a pretensão de se articular uma abordagem histórica linear. De fato, qualquer autor que tenha uma coesão mínima no seus conceitos e métodos de pesquisa, pode ser tratado dessa maneira.

A título de exemplo, comentarei brevemente o recorte que tenho feito na disciplina Arte e Educação do curso de Pedagogia da UNIRIO, onde leciono atualmente. Tendo em vista que os cursos de Pedagogia visam a formação de um professor generalistas, que irá atuar no Ensino Fundamental abordando todas as disciplinas curriculares, inclusive as diversas linguagens artísticas, minha questão era: Como preparar minimamente um pedagogo para o ensino de artes visuais, tendo apenas uma disciplina de 60 horas para fazê-lo?

Com o objetivo de estimular e desinibir os alunos a falarem sobre as artes visuais e demais imagens que povoam seu cotidiano, inicio o curso com a oficina sobre Jakobson, comentada acima. Em seguida, trabalho com Wölfflin (1984), autor que numa perspectiva estritamente formal, faz uma análise comparativa entre as estruturas de composição visual do Renascimento e do Barroco, reduzindo-as a cinco pares de características antagônicas ${ }^{3}$. Meu interesse ao resgatá-lo não é propriamente o estudo da História da Arte, mas sim a análise dos fundamentos da linguagem visual. Exatamente por ser contextualizada na análise de imagens, a teoria de Wölfflin permite o acesso à "gramática visual", articulando seus aspectos morfológicos (linha, ponto, plano etc.) e sintáticos (equilíbrio, movimento, direção etc.), de modo muito semelhante ao requisitado pelas novas metodologias para o ensino da Língua Portuguesa, comentadas anteriormente.

3 Denominadas genericamente como Linear e Pictórico, os cinco pares de características antagônicas entre o Renascimento e o Barroco analisados por Wölfflin são respectivamente: linear X pictórico, plano $X$ profundidade, unidade $X$ pluralidade, forma fechada $X$ forma aberta, clareza absoluta $X$ clareza relativa. 
No entanto, essa priorização do estudo dos fundamentos da linguagem visual não impede a remissão à análise da História da Arte. Mantendo ainda uma abordagem formalista, a partir da consideração de Wölfflin (1984) de que "o linear e o pictórico (...) são como dois idiomas através dos quais tudo pode ser dito", mostro aos alunos que aquela oposição estilística entre o Renascimento e o Barroco pode ser observada em estilos artísticos anteriores e posteriores a eles. Nesse exercício, estando os alunos já "alfabetizados nos métodos Wölfflin e Ostrower", criamos, em apenas uma ou duas aulas, uma linha do tempo sobre a História da Arte, desde a pré-história até a atualidade, focalizando a arte ocidental hegemônica. Ao longo dessas análises formais algumas informações sobre o contexto histórico desses estilos vão sendo inseridas.

Quanto aos estilos posteriores ao Renascimento e Barroco, desfruto com meus alunos o privilégio de ter na cidade do Rio de Janeiro o Museu Nacional de Belas Artes (MNBA), detentor da maior coleção de arte brasileira do século XIX. Em torno dessa coleção são comentados o Neoclassicismo e o Romantismo, estilos que resgatam, de modo programático, as sintaxes Linear e Pictórica, discutidas por Wölfflin em relação ao Renascimento e ao Barroco.

Nesta visita solicito que os alunos escolham duas obras, uma Linear e outra Pictórica, nos demais pavilhões do museu, que tratam do modernismo e da arte contemporânea. Sobre essas duas obras eles produzem um texto crítico aplicando os conceitos de Jakobson, Wölfflin e Ostrower, sem qualquer pesquisa na internet, já que isso será realizado numa próxima atividade.

Por fim, discuto de modo bem sintético as formulações de Bazin (1989) sobre os diferentes métodos da História da Arte. Posto que a narrativa historiográfica também é um processo comunicativo, faço essa discussão resgatando os conceitos de Jakobson.

Seguindo a ordem cronológica do advento das diferentes metodologias, observamos que o método biográfico enfatiza a vida do artista-Emissor. O método Arqueológico prioriza o Canal, ao analisar a materialidade da arte (pigmentos, suportes, técnicas etc.) para datá-la historicamente ou verificar sua autenticidade. $\mathrm{O}$ 
método formalista e a Iconologia têm seu foco no Código, sendo que o primeiro explora a gramática visual e o segundo o teor simbólico das formas artísticas. Devido à sua abordagem macro cultural, a Iconologia e a Antropologia já demarcam um nexo com o contexto Referencial, porém no método sociológico essa referencialidade é mais pontual, escrutinando como as características sociais, políticas e econômicas do local e época em que viveu o artista se manifestam em sua obra. Ao final, acrescento às discussões feitas por Bazin a abordagem pós-moderna da História da Arte que, em larga medida, investiga a questão do Receptor. Ou seja, discute como as mulheres, os negros, os pobres e demais "minorias" se veem representadas na tradição artística.

Após essa discussão, peço que os alunos façam a citada pesquisa na internet sobre os dois artistas escolhidos na visita ao museu. Nesta atividade eles não precisam escrever nada, apenas "copiar e colar" os textos que encontrarem. Porém, terão de lê-los com muita atenção com o objetivo de identificar fragmentos que exemplifiquem as questões de cada um dos métodos da História da Arte discutidos.

Como a maioria das narrativas sobre a vida e obra dos artistas que encontramos na internet costumam ser muito ecléticas em sua abordagem, é possível que o aluno encontre todos os exemplos num único texto. Caso isso não ocorra, peço que pesquisem até três textos. Se mesmo assim não encontrarem todos os exemplos, explico que não há problema, pois isso apenas demostra como certos aspectos sobre a arte são sempre discutidos, enquanto outros são negligenciados, de modo que o campo de pesquisa da História da Arte, como de tudo mais, está sempre aberto a novas investigações. O importante é que a partir dessa atividade, além de apreciarem as obras de arte e exercitarem o fazer artístico ${ }^{4}$ (Figura 3), eles estão aprendendo, também, a analisar criticamente as narrativas historiográficas sobre a arte.

4 Exposição de trabalhos dos alunos (1/2016): texto sobre características físicas/Naturalismo, psicológicas/Expressionismo e Acróstico/Idealismo com o próprio nome, além de autorretrato feito em acetato sobre espelho. Pintura de autorretrato Linear e Pictórico nas duas faces de uma placa de papelão. 
Figura 3 - Exposição de trabalhos dos alunos (2016/1).
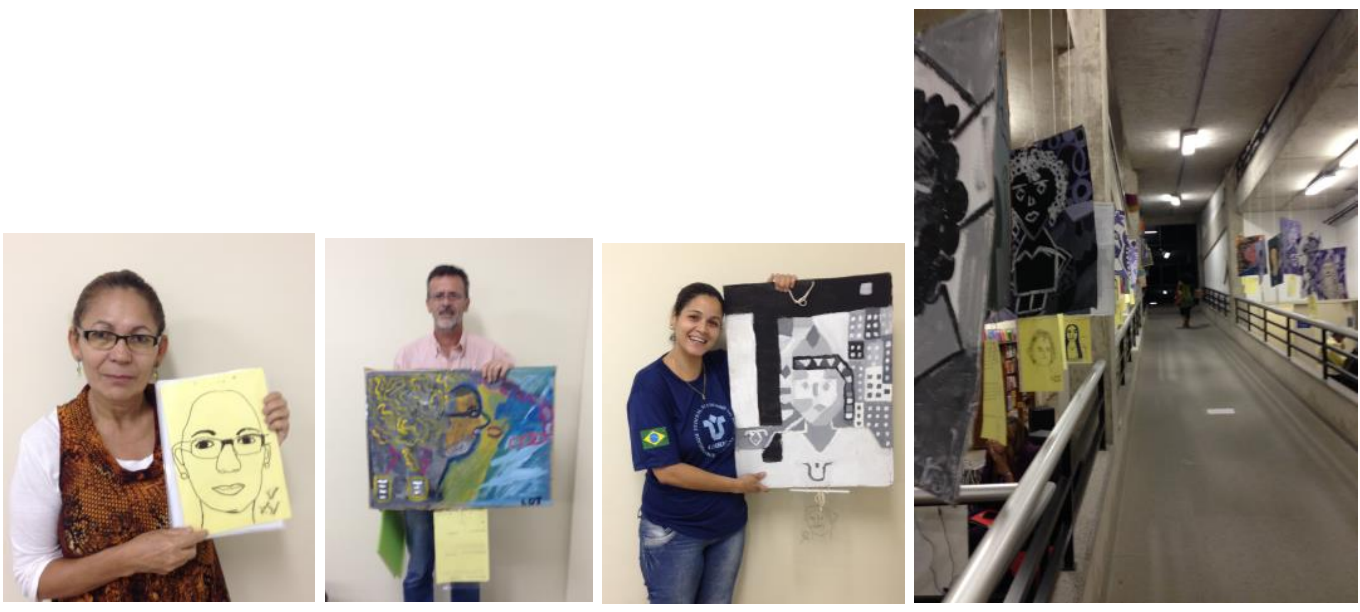

Fonte: Arquivo da autora.

Ainda explorando Jakobson, ao longo do curso os alunos realizam atividades pontuais de planejamento didático, aplicando a Abordagem Triangular. Mesmo que criem ótimas propostas, costumo pedir que refaçam aquele planejamento utilizando outras tônicas do processo comunicativo, apenas para dimensionarem a diversidade de caminhos possíveis na triangulação entre o Fazer, o Apreciar e o Contextualizar.

Articulada à minha atividade docente, sistematizei essas pesquisas na tese de doutorado denominada "A interpretação da imagem: subsídios para o ensino de arte". Ela foi defendida em 2005, na Escola de Comunicação e Artes, da Universidade de São Paulo (ECA/USP), sob a orientação da professora Ana Mae Barbosa, por quem tenho profunda gratidão e respeito, tanto acadêmica, quanto humana.

\section{Referências}

ARNHEIM, Rudolf. Arte e percepção visual. São Paulo: Pioneira, 1984.

BARBOSA, Ana Mae. A imagem no ensino da Arte. São Paulo: Perspectiva, 1991.

BARBOSA, Ana Mae; CUNHA, Fernanda Pereira (Orgs.). Abordagem Triangular no ensino das artes eculturas visuais. São Paulo: Cortez, 2010.

BAZIN, Germain. História da história da arte. São Paulo: Martins Fontes, 1989.

BRASIL. Ministério da Educação. Parâmetros Curriculares Nacionais. Brasília: MEC, 1998.

CHALHUB, Samira. Funções da linguagem. São Paulo: Ática, 1990.

GOMBRICH, Ernst. Arte e ilusão. São Paulo: Martins Fontes, 1986.

HABERMAS, Jürgen. Modernidade versus pós-modernidade. Arte em Revista, ano 5, n. 7, p. 86-91, ago. 1983.

JAKOBSON, Roman. Linguística e comunicação. São Paulo: Cultrix, 1969. 
LOSADA, Terezinha. A interpretação da imagem: subsídios para o ensino de arte. Rio de Janeiro: FAPERJ/Mauad, 2011.

OSTROWER, Fayga. Universos da arte. Rio de Janeiro: Campus, 1984.

PEIRCE, Charles S. Semiótica. São Paulo: Perspectiva, 1977.

SANTAELLA, Lucia. Por uma classificação da linguagem visual. Face, v. 2, n. 1, p. 43-67, jan./jun. 1989.

SANTAELLA, Lucia. Matrizes da linguagem e do pensamento: sonora, visual, verbal. São Paulo: lluminuras, 2001.

WÖLFFLIN, Heinrich. Conceitos fundamentais da história da arte. São Paulo: Martins Fontes, 1984.

\section{Terezinha Losada}

Artista plástica e Professora Associada da Universidade Federal do Estado do Rio de Janeiro (UNIRIO). Possui graduação em Licenciatura em Educação Artística Artes Plásticas pela Universidade de Brasília (1983), mestrado em Educação pela Universidade Federal do Piauí (1995), doutorado em Artes pela Universidade de São Paulo (2005) e doutorado em Centre for Art Education and International Research - University of Surrey Roehampton (2004). Tem experiência na área de linguagem, com ênfase nos seguintes temas: interpretação da imagem, história da arte, ensino de arte e educação à distância.

E-mail: telosada@gmail.com

Currículo: http://lattes.cnpq.br/0364208584436467

Recebido em 14 de março de 2017

Aceito em 26 de junho de 2017 